\title{
Mobile Cloud Learning for Higher Education: A Case Study of Moodle in the Cloud
}
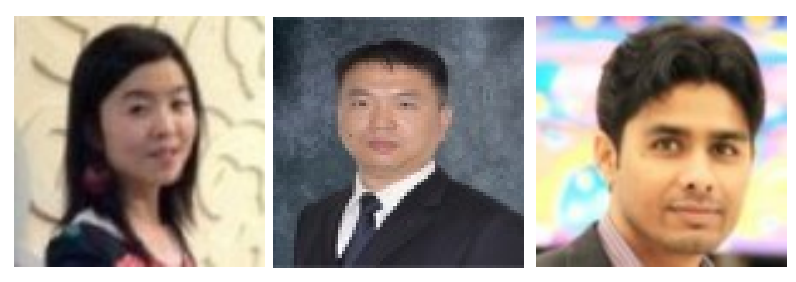

Minjuan Wang ${ }^{1}$, Yong Chen ${ }^{2}$, and Muhammad Jahanzaib Khan ${ }^{3}$ ${ }^{1}$ San Diego State University, USA and Shanghai International Studies University (Oriental Scholar), ${ }^{2}$ Old Dominion University, USA, 3Higher College of Technology, UAE

\section{Abstract}

Mobile cloud learning, a combination of mobile learning and cloud computing, is a relatively new concept that holds considerable promise for future development and delivery in the education sectors. Cloud computing helps mobile learning overcome obstacles related to mobile computing. The main focus of this paper is to explore how cloud computing changes traditional mobile learning. A case study of the usage of Moodle in the cloud via mobile learning in Khalifa University was conducted.

Keywords: Cloud computing; mobile learning; mobile cloud learning; Moodle; higher education 


\section{Introduction}

The rapid progress of mobile technology becomes a powerful trend in the development of mobile learning (Bai, Shen, Chen, \& Zhuo, 2011). However, due to the high costs of mobile devices, networks, low network transmission rate, and limited education resources, mobile learning is not widely deployed ( $\mathrm{Li}, 2010)$. With the continuous rapid development and widespread applications of new information technologies, cloud computing is bringing major changes and new breakthroughs in teaching and learning. It is becoming the dominant method in which mobile, online, and other types of applications operate (Rao, Sasidhar, \& Kumar, 2010).

Cloud computing is "a model for enabling ubiquitous, convenient on-demand network access to a shared pool of configurable computing resources (e.g., networks, servers, storage, applications, and services) that can be rapidly provisioned and released with minimal management effort or service provider interaction" (Mell \& Grance, 2009). It has two inherent characteristics: elasticity (resource scaling up) and resource pooling (running various independent services) (Hirsch \& Ng, 2011). Cloud computing makes up the inadequacies of mobile learning and leads to a revolution in mobile learning. Cloud computing can store a huge amount of educational resources and provide infrastructure, platform, and application services for users instead of letting users save them in their devices ( $\mathrm{Li}, 2010)$. It can also provide unlimited computing power for the completion of various types of application (Chen, Liu, Han, \& Xu, 2010).

Mobile cloud learning is an amalgamation between cloud computing and mobile learning (Hirsch \& $\mathrm{Ng}, 2011$ ). It integrates the cloud computing into the mobile environment and overcomes obstacles related to mobile computing (Dinh, Lee, Niyato, \& Wang, 2011). In this paper, we examine mobile cloud learning and explore how it can be used in higher education. We achieve this through a brief case study of the implementation of Mobile Moodle in Khalifa University, Abu Dhabi, UAE.

\section{Background}

\section{Definition of Mobile Cloud Learning}

Mobile cloud learning (Figure 1), a novel unification of cloud computing and mobile learning, is a relatively new concept that holds great promise for future development of education (Hirsch \&Ng, 2011). 


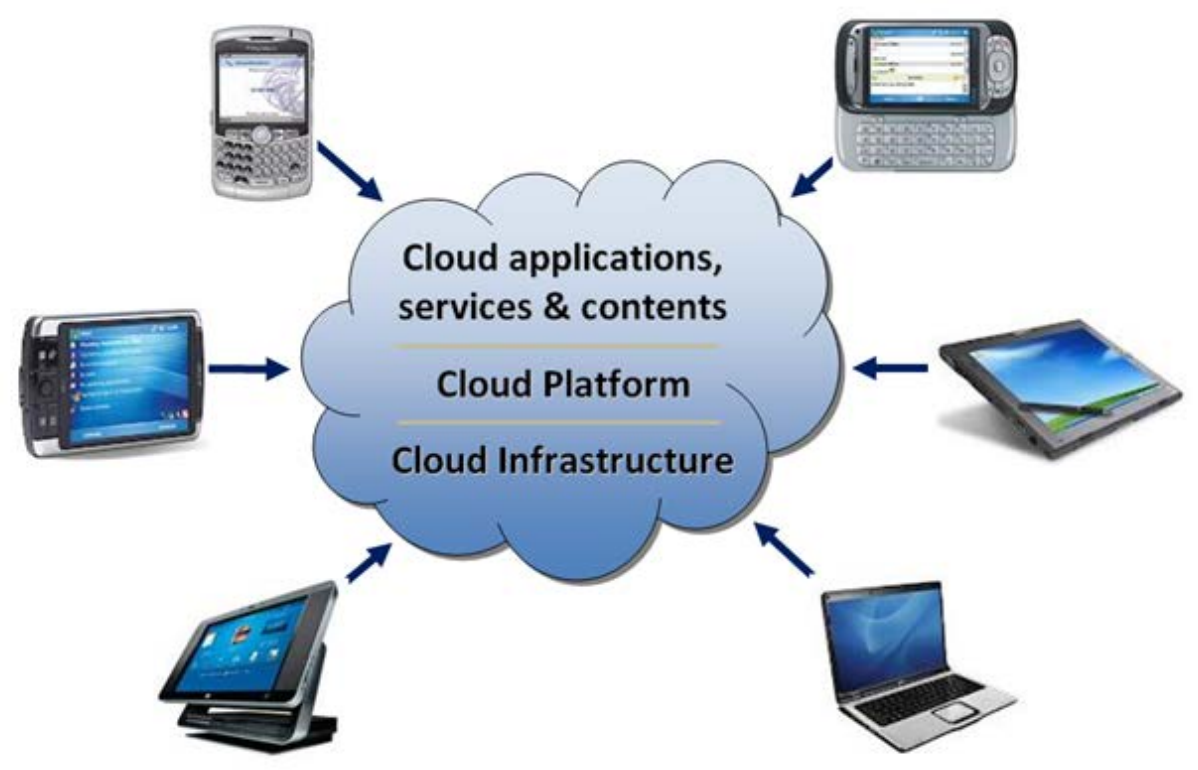

Figure 1. The concept of mobile cloud learning (Hirsch \& Ng, 2011).

Mobile learning has been evolving, from the early definitions of "learning with mobile devices" (Harris, 2011; Kossen, 2001) to the current terminology that emphasizes learner mobility, resulting from the use of mobile devices. The shift of the mobile learning definition changes the focus from mobile devices to mobile learners, and requires designers not to design instructions for a new class of mobile technologies, but to broaden their perspectives of what mobility for the learner entails in relation to learning. Only after recognizing this focus shift in design can designers identify a dichotomy of guidelines with one set focusing on the technology and one set focusing on the learner. In addition, mobile learning research from mobile learners' perspectives require the study of "... how the mobility of learners augmented by personal and public technology can contribute to the process of gaining new knowledge, skills, and experience" (Sharples, Arnedillo-Sánchez, Milrad, \& Vavoula, 2009). This multidimensional view of mobility greatly enriches the discourse in mobile learning and also poses new directions for research and development in this field.

Mobile learning enables learners to acquire learning content anytime anywhere via portable devices. But low processing power and memory constraints of mobile devices, expensive network connection fees, slow network transmission, and limited educational resources fundamentally limit the development of mobile learning ( $\mathrm{Li}, 2010)$. Mobile cloud learning integrates cloud computing into mobile learning. The advantages of cloud computing, such as massive data storage, high-performance computing, and easy access overcome obstacles related to mobile learning (Dinh, Lee, Niyato, \&Wang, 2011). Figure 2 shows the architecture of mobile cloud learning. In mobile cloud learning, learners can access content, such as text-based documents, audio, and video files, over 
the Cloud via their mobile devices connected with the Internet (such as GPRS, UMTS, HSPA, WiFi, WiMAX, or LTE) (Rao, Sasidhar, \& Kumar, 2010; Kitanov \& Davcev, 2012).

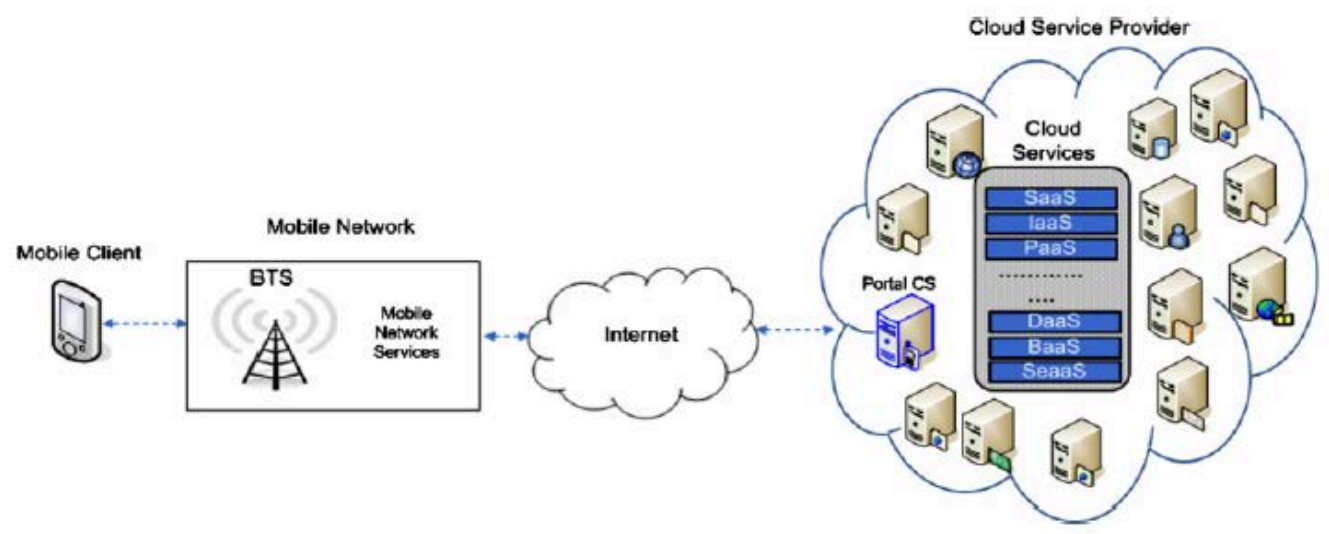

Figure 2. Mobile cloud learning architecture (Khan, Kiah, Khan, \& Madani, 2012).

\section{Benefits of mobile cloud learning.}

Traditional mobile learning must deal with the following drawbacks-high device and network costs, low network transmission rates, and limited education resources available. Combining the advantages of mobile learning and cloud computing, mobile cloud learning is introduced to solve these limitations (Kitanov \& Davcev, 2012). Weber (2011) argues "greater connectivity between centralized server-side applications and low cost/low processor capacity mobile devices could provide better access, more control, and greater freedom for e-learners" (p. 565).

Mobile cloud learning has a number of benefits to both the content providers and the learners. First and foremost, it costs less. For content providers, it saves the large initial cost, spending on hardware and software incurred when installing all kinds of systems (Freeman, 2000). By paying regular monthly fees, even small schools and universities, which cannot justify the return-on-investment for the high initial setup costs can provide mobile cloud learning services without spending large set-up costs for infrastructure (Hirsch $\& \mathrm{Ng}$, 2011). In addition, they do not need to instantly maintain and upgrade hardware or software. Meanwhile, because all computing, storage, and updates are completed on the cloud side, mobile devices serve for display only (Mohamudally, 2011). As a result, users can utilize web-based applications on their mobile devices with small memory spaces because there is no need for software loading and document saving (Rao, Sasidhar, \& Kumar, 2010). They can use variable mobile devices to access learning content without purchasing, installing, or updating any software. 
Second, mobile cloud learning can also be easily accessed as long as a mobile network is available. Palmer and Dodson (2011) point out that rural students, who do not have access to high-speed broadband Internet connections, can access curriculum content easily via 3G mobile technologies. They can use services from the cloud data center for learning selected topics over their mobile phones even when they are in a small village or remote area (Rao, Sasidhar, \& Kumar, 2010). Although one may need a subscription, mobile cloud learning is open access to everybody. The fact that people might access such a program through their mobile devices makes it convenient for them in any part of the world to access learning resources (Woodill, 2010).

Third, because learning resources stored in clouds are shared across different schools and universities, more educational resources are available for mobile cloud learning users. In addition, novel applications and services, which improve collaboration, can be implemented, such as collaboration tools between students of different institutions, social communities, and more (Hirsch \& Ng, 2011).

Finally, mobile cloud learning is also flexible and allows for adjustments, depending upon learners' needs. Since it is accessed through subscription, the user does not need to know where the learning sources are (Rittinghouse \& Ransome, 2009).

\section{Characteristics of mobile cloud learning.}

Mobile cloud learning has the following characteristics.

1) Storage and sharing: Learning outcomes and resources can be stored in the "Cloud," which provides almost unlimited store and computation capacities. Documents can be commonly edited and shared in the "Cloud," such as services provided by GoogleDocs, Live Skydrive, and Office Live.

2) Universal accessibility: Learners can study as long as they have access to the network. Mobile cloud learning also makes a low-cost access terminal possible, because software, applications, and data are all operated in the cloud servers. This improved accessibility can greatly benefit developing regions.

3) Collaborative interactions: Learners can cooperate anywhere in the "Cloud." From social learning perspectives, they can collaboratively build common knowledge through frequent and convenient interactions.

4) Learner centered: Mobile cloud learning is heavily people-oriented, which meets the individual needs of learners. Learners in the "Cloud" select suitable resources and can track their learning progress and outcomes.

Given the above characteristics, mobile cloud learning is mostly utilized to enable communication between educators and students, manage the teaching and learning processes, and add knowledge to interested and willing users, utilized among learners, and so on. (Chang, Bacigalupo, Wills, \&De Roure, 2010). 
The responses of learners to using this learning method are excellent. Most studies share the finding that currently young people natively communicate through the language of mobile phones, the Internet, and social networks. Today's learners have more readily embraced learning and educational technologies compared to other traditional learning methods, as these new learning methods allow them to share their knowledge and experiences through online sites. Learners have also been identified as exhibiting better learning behaviors, while using these learning technologies, since they are a flexible, 'fun' way to learn, and manageable (Sharif, 2010).

In a recent survey of students in a UAE university, a large percentage of learners (about $80 \%$ use laptops, mobile phones, or both regularly for their learning purposes. Kennington, Olinick, and Rajan (2010) found most learners revealed that gadgets, such as laptops and mobile phones, are must haves and that Internet access is absolutely necessary. Additionally, learners want learning environments to be freer and more comfortable than classrooms. They prefer informal places rather than formal ones. Mobile cloud learning provides such an opportunity, allowing learners to check their timetables, obtain tutor's notes/assignments, complete research, and even learn an entire course using the same process (Kennington, Olinick, \& Rajan, 2010).

\section{The Use of Mobile Cloud Learning in Middle Eastern Regions}

Although cloud computing has been introduced almost all over the world, developed countries use it more than their developing counterparts. Among the countries in the Middle East, some are highly developed, while others are still underdeveloped. These countries are in a Muslim region and have quite different life styles and perceptions of issues compared with non-Islamic countries. However, Islamic and non-Islamic countries share the same needs for advanced technologies, including the education sector (Eze \& Onyegegbu, 2006). More and more people, including girls and women, are becoming educated today than a number of years ago in these Islamic countries.

Even though many countries in the Middle East are Islamic countries, each is unique. Big challenges come from the heterogeneous nature of their economies, geography, politics, and cultures. The region has diverse languages, cultures, and religions, although the widely practiced religion is Islam. Consequently, special options must be considered in the process of designing and developing advanced technology applications, such as mobile cloud learning. For example, the economies of the countries in this region are not at the same level. Some countries are very wealthy due to the oil industry, while others are poor due to their locations in an arid to semi-arid area (J aatun, Zhao, \& Rong, 2010). Therefore, a special blend of policies about technology upgrades must be made to ensure the underdeveloped countries can afford the costs. In addition, the technology levels of the countries in this region are not the same. Some countries, such as UAE, are more advanced than other countries, which are still trying to adopt the ever-changing technology (Al-Zoube, El-Seoud, \&Wyne, 2010). 
According to Weber (2011), there is a widespread shortage of qualified information and communication technology (ICT) professionals, training programs, and trained elearning educational staff in the Middle East and North African region. Some Middle Eastern countries, such as Saudi Arabia, Bahrain, and Yemen, are experiencing the rumblings of dissent related to recent political upheavals in several North African countries. The society and educational initiatives in Middle East countries are undoubtedly disrupted. Therefore, renting computer platforms and scalable power becomes a reasonable option for educational institutions in this region to deal with the threat of potential destruction of hardware. Mobile cloud learning can be designed appropriately for a specific group of people or a specific region. Without using extra facilities, the information technology (IT) specialists may design the learning process to meet the requirements of people in remote areas or those who are not prosperous. For example, instead of having a one-time subscription, they may introduce a learning process where one can access the cloud through bundles. For Islam countries, the process may be designed for some of the Middle Eastern languages among others. This technology is also referred to as a borderless learning method, which means literacy can reach individual people in deeply remote areas where there are no libraries, tutors, and/ or schools (Xu, Wang, \& Li, 2011).

\section{Moodle in the Cloud}

Moodle is a widely adopted open source learning management system (LMS), also known as a course management system (CMS) or a virtual learning environment (VLE) (Bamiah, Brohi, \& Chuprat, 2012), which supports both small and large deployments (with several sites well beyond millions of users) and includes course management tools, various Web 2.0 technologies, online assessments, integration with plagiarism detection tools, integration with repositories and electronic portfolio software, and other features common to learning management systems. As Xhafa, Caballé, Rustarazo, and Barolli (2010) argue, " Moodle distinguishes for easy configuration and maintenance as well as content course creation. A great advantage of using Moodle is the easiness of content creation, including forum, questionnaires, tasks, wikis, chats, etc." (p. 207). According to Moodle Statistics, Moodle is present in 223 countries, at 70,736 sites, hosting 6,790,797 courses, and 63,218,611 users and 1,290,273 instructors. The top 10 countries using Moodle by registrations are shown in Table 1. 
Table 1

Top 10 Countries Using Moodle by Registrations

\begin{tabular}{lr} 
Country & Registrations \\
\hline United States & 12,087 \\
\hline Spain & 6,143 \\
\hline Brazil & 5,088 \\
\hline United Kingdom & 3,949 \\
\hline Germany & 2,962 \\
\hline Mexico & 2,897 \\
\hline Portugal & 2,163 \\
\hline Colombia & 1,940 \\
Australia & 1,720 \\
Italy & 1,692
\end{tabular}

The normal way of setting up Moodle is to install it on a Windows or a Linux server in a data center, and manage it as part of an IT system. The setting up requires large investments in hardware and software. If Moodle is hosted in the Cloud, no big investments are needed.

Take Azure of Microsoft as an example of a platform in the cloud. First, the original Moodle must be converted to operate on Azure. Moodle on Azure, an open source tool, can achieve the conversion automatically, while making minimal alterations to the original Moodle. It is used to migrate locally hosted Moodle to the cloud/Azure environment. The current version of Moodle on Azure, open for public download, is capable of converting original Moodle 2.2. It is composed of patches and support extensions that make Moodle run well on Azure, either as a new installation or as a reinstallation.

Then, the operation of Moodle on Azure will generate a package ready for uploading to Azure for deployment. The download and upload processes are necessary because this is the method to ensure that customized Moodle works on Azure. However, the uploaded package can be installed only on one virtual server on the cloud (Morgado \& Schmidt, 2012).

Now Moodle running in the cloud is ready for learners to access. Mobile learning learners can visit learning resources inside the Moodle stored in the cloud. In this way, education institutions do not need to purchase expensive web servers to host their learning management systems. They do not need to hire an information technology team to maintain and update these systems. For learners, they do not need to buy mobile devices that have huge storage space and strong computation ability. In this case, Moodle is running in the cloud and data are stored in the cloud too. All they need to do is access the learning materials with their mobile devices via the Internet. 


\section{Implementation of Mobile Moodle in the Cloud at Khalifa} University

The biggest benefits for Khalifa University to move Moodle to the cloud are that investments and resources to operate its own servers are saved. As a result, Khalifa Universtiy can focus on supporting learners and teachers/professors as needed. Another benefit to moving Moodle to the Cloud is off-campus users can access it via mobile devices, such as smart mobile phones and iPad.

Khalifa University currently runs Moodle Version 1.9. To implement Moodle on the cloud, Moodle was upgraded to Version 2.0 because newer versions are able to support smart phones correctly. The applications introduced by Moodle 2.0 are the predominant paradigm for mobile development. Some Moodle 2.0 applications are attractive, such as myMobile and mBot. Based on Moodle 2.0+ and JqueryMobile, myMobile is customized and optimized for supporting smart phone devices and tablets. As an Android application for Moodle, mBot remembers credentials, logs and pages users visit and lists assignments. It can also open Microsoft Office documents and even add users' classmates to their Google contacts. Moodle Apps 1.0, which can be customized as well, has several options to meet users' needs and requirements.

In addition, Banner, a student information system, is integrated with Moodle in Khalifa University. Although they both operate on the local/in-house Active Directory Server, their authentication mechanisms are different. In other words, even with the same username and password, users must logon to the two systems differently or ONE BY ONE. They cannot access the two systems with a single login. Unfortunately, moving Moodle to the cloud does not fix this issue. As Hirsch and Ng (2011) assert, integration is still one of the challenges for mobile cloud learning.

Technology integration in Khalifa University is based upon sound pedagogical foundations. Following social constructivism, the integration of Moodle and Banner aims to facilitate a student-centered learning environment. Another objective of the integration is to facilitate communications among students, between students and teachers, as well as between students and resources. 


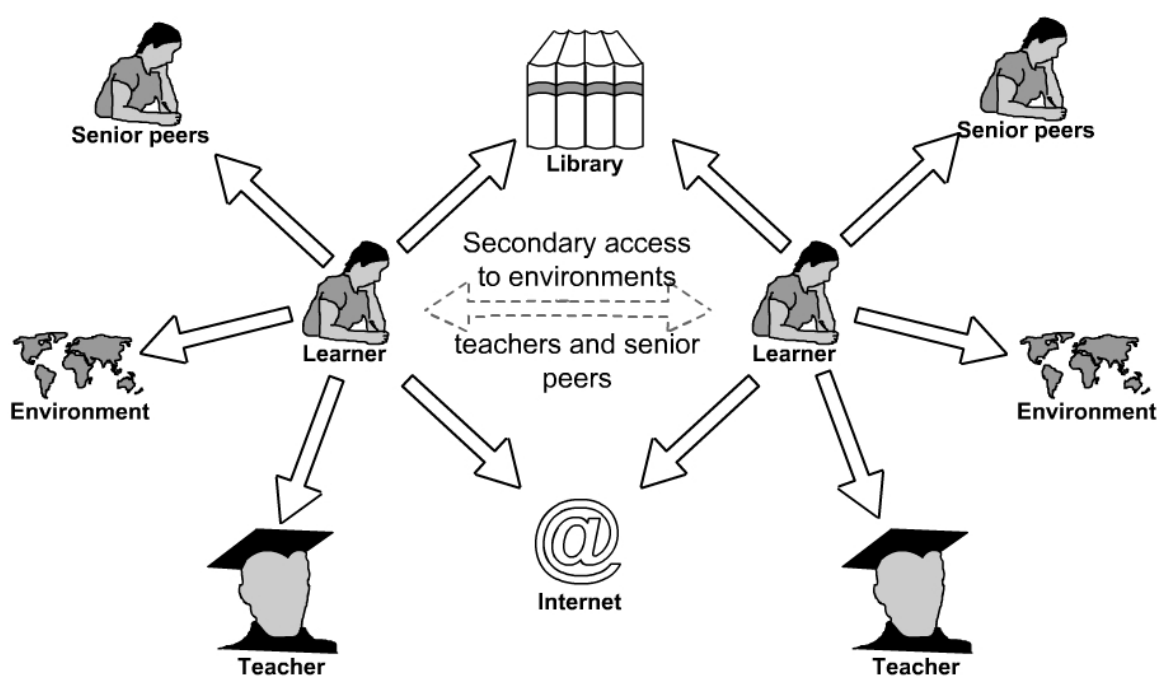

Figure 3. The learner centered collaborative environment.

Moodle in the cloud facilitates collaboration as well. Learning through social interactions is an important part of social constructivism. Learner-centered learning interactions provided by Moodle in the cloud not only improves learner engagement, but also develops personal intellect and understanding of the content. Learners have access to a wider range of resources, due to the collaboration between Khalifa University and nation-wide and international education sectors. For professors and teachers, collaborating with other researchers becomes convenient. Furthermore, the contact between instructors and learners expands off campus.

\section{Discussion}

Although Moodle is widely used in the education sector around the world, some instructors and students are unwilling to accept this technology. Even though Moodle is moved to the cloud, the problem of acceptance still exists. Ambraziene, Miseviciene, and Budnikas (2011) argue that the learning curve for mastering Moodle is high for instructors and students. Therefore, they do not use it very often-only for educational purposes. Students are unwilling to use Moodle because it does not have features to support their active communications and collaborations. Since social communication is an important aspect for learning (Mason, 2008) combining some social networking tools for education with Moodle may be helpful to facilitate learning and teaching.

Both Google and Microsoft offer free cloud email and collaboration services to educational institutions. Microsoft Live@edu, a cloud-based email system that contains communication tools, such as instant messaging along with contact management and calendar software, has a free plug-in for Moodle. Teachers and students can use Live@edu e-mail service, as well as other services, such as cloud storage of 25GB, data 
synchronization, instant messaging, and Microsoft Office applications in the browser (Ambraziene, Miseviciene, \&Budnikas, 2011).

Khalifa University can integrate Moodle with Live@edu email system by using a plug-in from Education Labs. In this way, Moodle can serve as the main portal of learning resources for students, whether they are on-campus or off-campus. Furthermore, the integration of Moodle and Live@edu provides students with a single sign-on to their email accounts, cloud storage space, and Moodle. Because Moodle turns into a part of students' active communications and collaborations, it is much easier to be accepted by users.

Meanwhile, the challenges in mobile cloud learning should not be overlooked.

1. Mobile network condition. Mobile cloud learning depends on learners' wireless connection. The quality of the mobile networks might not be adequate for delivering satisfactory user experience via the collaboration between mobile devices and cloud services (Hung, Shih, Shieh, Lee, \& Huang, 2012).

2. Control of applications. Learning materials are stored on the cloud and computations are performed on the cloud; learners are no longer in full control of applications (Hung, Shih, Shieh, Lee, \&Huang, 2012).

3. Security and privacy. Learners' sensitive information and their privacy can be easily violated when cloud providers utilize user data for claimed purposes (Dinh, Lee, Niyato, \&Wang, 2011; Hung, Shih, Shieh, Lee, \&Huang, 2012).

\section{Conclusion}

Mobile cloud learning positively influences the learning process, as seen from both educators and learners. Although it may be more cumbersome for some to access the program than others, it makes it easier for more people to obtain knowledge through their mobile devices without worrying much about other hardware. In other words, mobile cloud learning brings the classroom to the student unlike other traditional methods. It is of benefit not only to the learners but also to the educators in their classroom management. Meanwhile, learners must run the risks, such as losing control of applications and damage to personal information security and privacy, to take advantage of mobile cloud learning. 


\section{References}

Al-Zoube, M., Abou El-Seoud, S., \&Wyne, M. F. (2010). Cloud computing based elearning system. International J ournal of Distance Education Technologies (IJ DET), 8(2), 58-71.

Ambraziene, D., Miseviciene, R., \& Budnikas, G. (2011). Application of cloud computing at KTU: MS Live@ Edu Case. Informatics in Education-An International J ournal, 10(2), 259.

Bai, Y., Shen, S., Chen, L., \&Zhuo, Y. (2011, July). Cloud learning: A new learning style. In 2011 IEEE International Conference on Multimedia Technology (ICMT), 3460-3463.

Bamiah, M. A., Brohi, S. N., \& Chuprat, S. (2012). Using virtual machine monitors to overcome the challenges of monitoring and managing virtualized cloud infrastructures. In Fourth International Conference on Machine Vision (ICMV 11) (pp. 83491M-83491M). International Society for Optics and Photonics.

Chang, V., Bacigalupo, D., Wills, G., \&De Roure, D. (2010, May). A categorisation of cloud computing business models. In Proceedings of the 2010 10th IEEE/ ACM International Conference on Cluster, Cloud and Grid Computing (pp. 509-512). IEEE Computer Society.

Chen, X., Liu, J ., Han, J ., \&Xu, H. (2010). Primary exploration of mobile learning mode under a cloud computing environment. In E-Health Networking, Digital Ecosystems and Technologies (EDT), 2010 International Conference on (Vol. 2, pp. 484-487). IEEE.

Dinh, H. T., Lee, C., Niyato, D., \&Wang, P. (2011). A survey of mobile cloud computing: Architecture, applications, and approaches. Wireless Communications and Mobile Computing, 1587-1611.

Eze, D. N., \& Onyegegbu, N. (Eds.) (2006). Information communication technology (ICT) in the service of education (pp. 293-297). Enugu: Timex.

Freeman, H. (2000). The virtual university: The Internet and resource-based learning. Routledge.

Harris, P. (2001, J uly). Goin' mobile. Learning Circuits, ASTD Online Magazine.

Hirsch, B., \&Ng, J . W. (2011). Education beyond the cloud: Anytime-anywhere learning in a smart campus environment. In Internet Technology and Secured Transactions (ICITST), 2011 International Conference (pp. 718-723). IEEE.

Hung, S. H., Shih, C. S., Shieh, J . P., Lee, C. P., \&Huang, Y. H. (2012). Executing mobile applications on the cloud: framework and issues. Computers \& Mathematics with Applications, 63(2), 573-587. 
J aatun, M. G., Zhao, G., \& Rong, C. (Eds.). (2010, Dec.). Cloud computing. First International Conference, CloudCom 2009, Beijing, China, 2009, Proceedings (Vol. 5931). Springer.

Kennington, J ., Olinick, E., \& Rajan, D. (Eds.). (2010). Wireless network design: Optimization models and solution procedures. Springer.

Khan, A. N., Mat Kiah, M. L., Khan, S. U., \& Madani, S. A. (2012). Towards secure mobile cloud computing: A survey. Future Generation Computer Systems, 29, 1278- 1299.

Kitanov, S., \& Davcev, D. (2012). Mobile cloud computing environment as a support for mobile learning.In Cloud Computing 2012, The Third International Conference on cloud computing, GRIDs, and Virtualization (pp. 99-105).

Kossen, J . S. (2001). When e-learning becomes m-learning. Palmpower Magazine. Retrieved from http:/ / zatz.com/ computingunplugged/article/ when-e-learningbecomes-m-learning/

Li, J . (2010). Study on the development of mobile learning promoted by cloud computing. In IEEE 2010 2nd International Conference on Information Engineering and Computer Science (ICIECS), 1-4.

Mason, R. (2008). E-learning and social networking handbook: Resources for higher education. Routledge.

Mell, P., \&Grance, T. (2009). The NIST definition of cloud computing . Retrieved from http:// csrc.nist.gov/ publications/nistpubs/800-145/ SP800-145.pdf

Mohamudally, N. (2011). The technological challenges in mobile networks and communications in view of unleashing the full potential of m-learning. Formatex 2011. Retrieved from http:// www.formatex.info/ict/book/ 548555.pdf

Moodle. (2012). Statistics. Retrieved from http:// moodle.org/ stats

Morgado, E. M., \& Schmidt, R. (2012, J une). Increasing Moodle resources through cloud computing. In Information Systems and Technologies (CISTI), 2012 7th Iberian Conference (pp. 1-4). IEEE.

Palmer, R., \& Dodson, L. (2011). Distance learning in the cloud: Using $3 \mathrm{G}$ enabled mobile computing to support rural medical education. J ournal of the Research Center for Educational Technology, 7(1), 106-116.

Rao, N. M., Sasidhar, C., \& Kumar, V. S. (2010). Cloud computing through mobilelearning. Computing, 1(6). 
Rittinghouse, J . W., \& Ransome, J . F. (2009). Cloud security challenges. Cloud Computing: Implementation, Management, and Security, 158-161.

Sharif, A. M. (2010). It's written in the cloud: The hype and promise of cloud computing. J ournal of Enterprise Information Management, 23(2), 131-134.

Sharples, M., Arnedillo-Sánchez, I.A., Milrad, M., \& Vavoula, G. (2009). Mobile learning: Small devices, big issues. In S. L. Montandon, N. Balacheff, S. Ludvigsen, T. de J ong \&A. Lazonder (Eds.), Technology-enhanced learning: Principles and products (pp. 233- 251). Berlin: Springer-Verlag.

Weber, A. S. (2011). Cloud computing in education in the Middle East and North Africa (MENA) Region: Can barriers be overcome? In Conference proceedings of eLearning and Software for Education (No. 01, p. 565).

Woodill, G. (2010). The mobile learning edge: Tools and technologies for developing your teams. McGraw-Hill.

Xhafa, F., Caballé, S., Rustarazo, I., \& Barolli, L. (2010). Implementing a mobile campus Using MLE Moodle. In P2P, Parallel, Grid, Cloud and Internet Computing (3PGCIC), 2010 International Conference on (pp. 207-214). IEEE.

Xu, B., Wang, N., \& Li, C. (2011). A cloud computing infrastructure on heterogeneous computing resources. J ournal of Computers, 6(8), 1789-1796.

\section{Athabasca University $\mathbf{a}$}

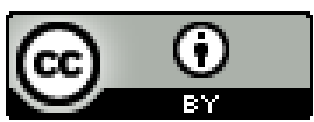

